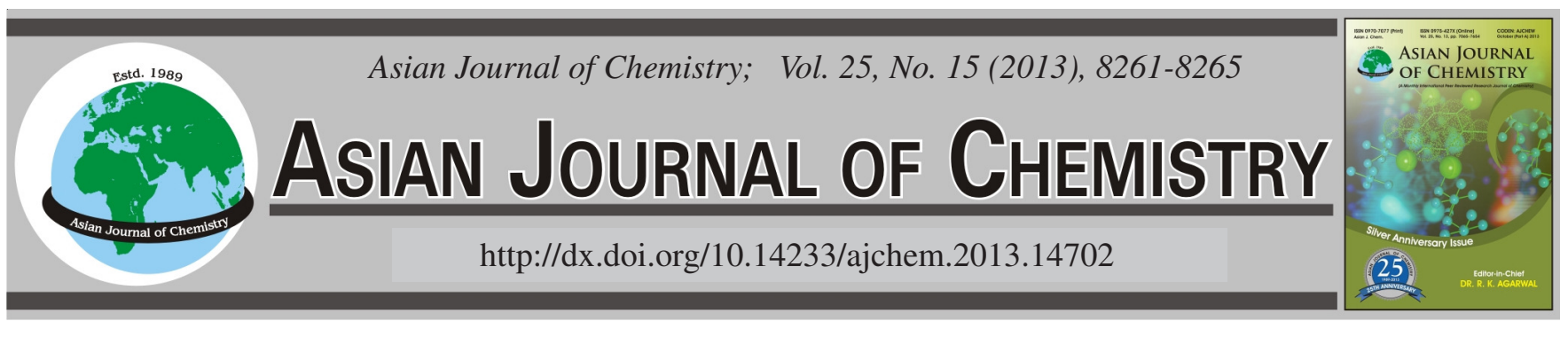

\title{
Mass Spectrometry of Ionic Liquids: ESI-MS/MS Studies
}

\author{
Gaurav R. Gupta ${ }^{1}$, Ganesh R. Chaudhari ${ }^{2}$, Preeti A. Tomar ${ }^{3}$, Yogesh Gaikwad ${ }^{4}$, \\ Azad Rameez ${ }^{4}$, Girish H. Pandya ${ }^{4}$, Govinda P. Waghulade ${ }^{5}$ and Kesharsingh J. Patil ${ }^{1, *}$
}

\author{
${ }^{1}$ School of Chemical Sciences, North Maharashtra University, Jalgaon-425 001, India \\ ${ }^{2}$ Department of Chemistry, M.J. College, Jalgaon-425 001, India \\ ${ }^{3}$ JSPM's Rajarshi Shahu College of Engineering, Pune-411 027, India \\ ${ }^{4}$ Anacon Laboratories, Nagpur-440 001, India \\ ${ }^{5}$ Department of Chemistry, D.D.N. Bhole College, Bhusawal-425 201, India \\ *Corresponding author: E-mail: patilkesharsingh@ @otmail.com
}

\begin{abstract}
Herein, we reported our studies related to structural elucidation and gas-phase fragmentation patterns of the imidazolium and pyridinium based ionic liquids, using a positive ion electrospray ionization triple quadrupole mass spectrometry. Ionic liquids mainly imidazolium/ pyridinium/alkylammonium salts, possess properties due to which there are many applications from the point of view of green chemistry. The recorded mass spectral patterns are presented and possible pathways for fragmentations are suggested. The mass spectrum of tetrabutylammonium bromide and its fragmentation pattern is discussed since we used this compound as a template in the synthesis of ionic liquids. Our analysis also suggests possibilities of associations of ions in the form of $\mathrm{C}_{2} \mathrm{~A}^{+}$species in vapour phase for the studied ionic liquids.
\end{abstract}

Key Words: Ionic liquids, Electrospray ionization mass spectrometry, Tetrabutylammonium bromide, Triplet interactions.

\section{INTRODUCTION}

Ionic liquids have seized the imagination of the scientific community, because of their large application window in electrochemistry $^{1}$, separation science ${ }^{2}$, as a promising green replacement of volatile organic compounds in the organic synthesis and catalysis ${ }^{3}$. Though the numerous application window of ionic liquids have been generalized, yet the effective utilization of ionic liquids is still not achieved and reason behind this is the time consuming synthetic route and after synthesis, characterization of ionic liquids as well. Consequently, there is a need for development of an efficient strategy for their synthesis as well as their analysis, establishment of such strategies not only play a crucial role in the assessment of the purity of ionic liquids, but also to check their suitability for the process where ionic liquids are involved.

Electrospray ionization is a powerful tool in the arsenal of mass spectrometry, the continued existence of huge literature manifests its importance in the field of drugs and pharmaceuticals ${ }^{4}$, lipidomics ${ }^{5}$, chemical analysis ${ }^{6}$, environment science $^{7}$ and polymer analysis ${ }^{8}$. To our best of knowledge, only a few published reports deal with mass spectral analysis of $\mathrm{Ils}^{9}$. In the present paper, we report an ESI-MS/MS spectral analysis of (a) tetrabutyl ammonium bromide, (b) 1-ethyl-3- methylimidazolium bromide, (c) 1-methyl-3-propylimidazolium bromide, (d) 1-butyl-3-methylimidazolium bromide and (e) $n$-butylpyridinium bromide. We include pyridinium salt in the category of ionic liquids although it has a melting point higher than $100^{\circ} \mathrm{C}$. The aqueous chemistry of tetraalkylammonium salts is very important. Such salts also form clathrate-hydrates ${ }^{10}$. The properties like heat capacity, partial molal volumes and entropies have lead to concepts like hydration, solute-solute hydrophobic interaction, micellization, water structure making effect, etc. ${ }^{11,12}$. Therefore it was felt that the mass spectral study of this compound would be interesting. The mass spectrum is presented and analyzed.

\section{EXPERIMENTAL}

All ionic liquids were synthesized in the laboratory. The details of the synthetic methodology and spectral characterization (FT-IR and ${ }^{1} \mathrm{H}$ NMR) have been reported in our recent publication $^{13}$. We carried out the mass analysis with the help of TSQ Quantum Access triple stage quadrupole mass spectrometer system by Thermo Scientific (USA). The system also consists of Finnigan Surveyor Auto-sampler Plus and Surveyor MS pump Plus. The system was tuned by infusing a low concentration of tuning and calibrating solution that contains polytyrosine-1,3,6-directly into the H-ESI source using a 
syringe pump at a flow rate of $2 \mu \mathrm{L} / \mathrm{min}$ so as to achieve the best ion beam intensity and stability, the singly charged, positive ions for polytyrosine monomer, trimer and hexamer: $\mathrm{m} / \mathrm{z}$ 182, 508 and 997, respectively were observed.

The system was then flushed with the mobile phase methanol:formic acid $(0.1 \%)$ in the composition of 75:25. A full scan positive mode analysis of the sample in the Q1MS mode was carried out to find out the parent masses of the various ionic liquids. The parent masses of the ionic liquids are summarized in Table-1. The system was then operated in the MS +MS/ MS mode for optimization by introducing sample in the manual loop injection. The instrumental MS/MS conditions were: spray voltage: - $4500 \mathrm{~V}$, vaporizer temperature: $-150 \mathrm{~V}$, sheath gas pressure: -40 , auxiliary gas pressure: -15 , capillary temperature: $-300 \mathrm{~V}$ and the collision pressure: $-1.5 \mathrm{~m}$ Torr. The sample was injected and data acquisition was carried out for all the ionic liquids. The masses of the compounds in the sample were identified in this mode. Argon was used as a collision gas and nitrogen as a nebulizing gas.

\section{RESULTS AND DISCUSSION}

ESI-MS/MS was successfully applied to the characterization of the product obtained from Menschutkin quaternization reaction (synthesis of ionic liquids) of 1-methylimidazole and pyridine with alkyl halide(s) by employing molten tetrabutyl ammonium bromide as a template. The details of mass spectrums of the template used and all the four synthesized ionic liquids are presented in Figs. 1-5 and discussed below. In addition to this, we present here a likely detailed pattern of fragmentation, which is evidenced earlier in the literature by using different ionisation methods. This involves the migration of $\beta$-proton with subsequent removal of the neutral species i.e., alkenes, ring expansion through tropylium ion, loss of alkane, the McLafferty rearrangement and the removal of heterocycle i.e., aziridine and pyridine.

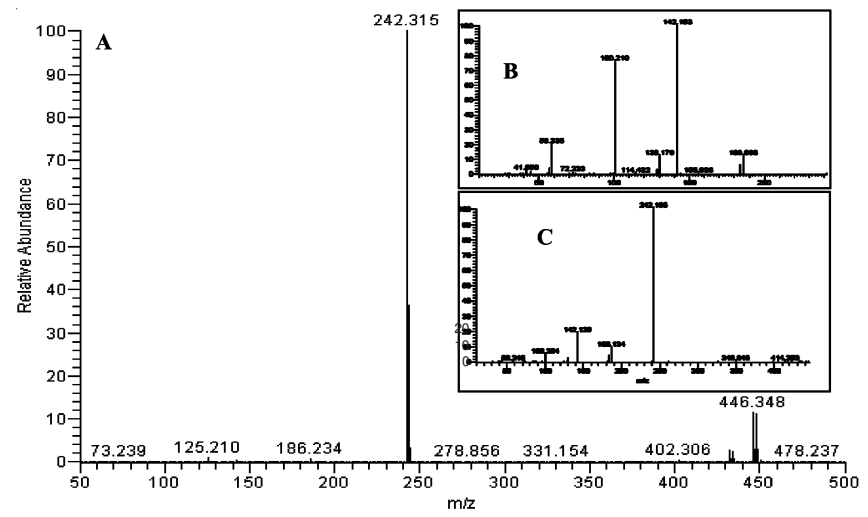

Fig. 1. ESI-MS/MS spectrum of compoundtetrabutyl ammonium bromide. The inset describes the resolution of the parent tetrabutyl ammonium cation of tetrabutyl ammonium bromide

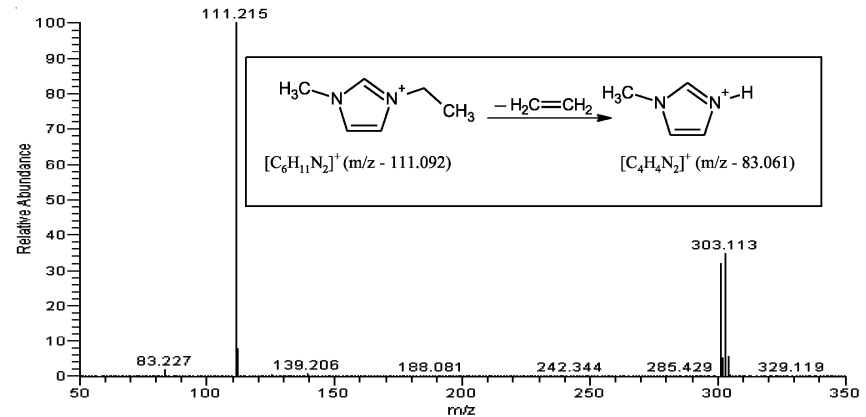

Fig. 2. ESI-MS/MS spectrum with proposed pattern of fragmentation of compound 1-ethyl-3-methylimidazolium bromide

The ESI-MS/MS spectral data obtained for tetrabutyl ammonium ion is depicted in Table-1 (entry 1a-1j) and obtained pattern is shown in Fig. 1. The thermal decomposition mass spectrum for the said compound (tetrabutyl ammonium cation) is reported in the literature ${ }^{9 g}$ and shows close resemblance with the present profile. The literature data have been explained on

\begin{tabular}{|c|c|c|c|c|}
\hline \multicolumn{5}{|c|}{$\begin{array}{c}\text { TABLE-1 } \\
\text { ESI-MS/MS DATA FOR COMPOUND a-e }\end{array}$} \\
\hline Compound & Entry & Observed $\mathrm{m} / \mathrm{z}$ & Calculated $\mathrm{m} / \mathrm{z}$ & Formula \\
\hline \multirow{10}{*}{$\begin{array}{l}\text { (a) Tetrabutylammonium } \\
\text { bromide }\end{array}$} & $1 \mathrm{a}$ & 446.348 & 446.541 & {$\left[\mathrm{C}_{28} \mathrm{H}_{68} \mathrm{~N}_{3}\right]^{+}$} \\
\hline & $1 b$ & 414.253 & 414.479 & {$\left[\mathrm{C}_{26} \mathrm{H}_{60} \mathrm{~N}_{3}\right]^{+}$} \\
\hline & $1 \mathrm{c}$ & 349.848 & 351.237 & {$\left[\mathrm{C}_{17} \mathrm{H}_{40} \mathrm{~N}_{2} \mathrm{Br}\right]^{+}$} \\
\hline & $1 d$ & 242.315 & 242.285 & {$\left[\mathrm{C}_{16} \mathrm{H}_{36} \mathrm{~N}\right]^{+}$} \\
\hline & $1 \mathrm{e}$ & 186.234 & 186.222 & {$\left[\mathrm{C}_{12} \mathrm{H}_{28} \mathrm{~N}\right]^{+}$} \\
\hline & 1f & 142.129 & 142.159 & {$\left[\mathrm{C}_{9} \mathrm{H}_{20} \mathrm{~N}\right]^{+}$} \\
\hline & $1 \mathrm{~g}$ & 130.179 & 130.160 & {$\left[\mathrm{C}_{8} \mathrm{H}_{20} \mathrm{~N}\right]^{+}$} \\
\hline & $1 \mathrm{~h}$ & 100.204 & 100.113 & {$\left[\mathrm{C}_{6} \mathrm{H}_{14} \mathrm{~N}\right]^{+}$} \\
\hline & $1 \mathrm{i}$ & 72.239 & 72.081 & {$\left[\mathrm{C}_{4} \mathrm{H}_{10} \mathrm{~N}\right]^{+}$} \\
\hline & $1 \mathrm{j}$ & 58.245 & 58.066 & {$\left[\mathrm{C}_{3} \mathrm{H}_{8} \mathrm{~N}\right]^{+}$} \\
\hline \multirow{3}{*}{$\begin{array}{l}\text { (b) 1-Ethyl-3- } \\
\text { methylimidazolium } \\
\text { bromide }\end{array}$} & $2 \mathrm{a}$ & 303.113 & 302.111 & {$\left[\mathrm{C}_{12} \mathrm{H}_{22} \mathrm{~N}_{4} \mathrm{Br}\right]^{+}$} \\
\hline & $2 b$ & 111.215 & 111.092 & {$\left[\mathrm{C}_{6} \mathrm{H}_{11} \mathrm{~N}_{2}\right]^{+}$} \\
\hline & $2 \mathrm{c}$ & 83.227 & 83.061 & {$\left[\mathrm{C}_{4} \mathrm{H}_{7} \mathrm{~N}_{2}\right]^{+}$} \\
\hline \multirow{2}{*}{$\begin{array}{l}\text { (c) 1-Methyl-3- } \\
\text { propylimidazolium } \\
\text { bromide }\end{array}$} & $3 b$ & 125.225 & 125.108 & {$\left[\mathrm{C}_{7} \mathrm{H}_{13} \mathrm{~N}_{2}\right]^{+}$} \\
\hline & $3 c$ & 83.265 & 83.061 & {$\left[\mathrm{C}_{4} \mathrm{H}_{7} \mathrm{~N}_{2}\right]^{+}$} \\
\hline \multirow{4}{*}{$\begin{array}{l}\text { (d) 1-Butyl-3- } \\
\text { methylimidazolium } \\
\text { bromide }\end{array}$} & $4 a$ & 359 & 358.170 & {$\left[\mathrm{C}_{16} \mathrm{H}_{30} \mathrm{~N}_{4} \mathrm{Br}\right]^{+}$} \\
\hline & $4 b$ & 139.174 & 139.124 & {$\left[\mathrm{C}_{8} \mathrm{H}_{15} \mathrm{~N}_{2}\right]^{+}$} \\
\hline & $4 c$ & 83.209 & 83.061 & {$\left[\mathrm{C}_{4} \mathrm{H}_{7} \mathrm{~N}_{2}\right]^{+}$} \\
\hline & $4 d$ & 41.486 & 42.034 & {$\left[\mathrm{C}_{2} \mathrm{H}_{4} \mathrm{~N}\right]^{+}$} \\
\hline \multirow{3}{*}{$\begin{array}{l}\text { (e) } n \text {-Butylpyridinium } \\
\text { bromide }\end{array}$} & $5 a$ & 351.3 & 351.143 & {$\left[\mathrm{C}_{18} \mathrm{H}_{28} \mathrm{~N}_{2} \mathrm{Br}\right]^{+}$} \\
\hline & $5 b$ & 136.127 & 136.113 & {$\left[\mathrm{C}_{9} \mathrm{H}_{14} \mathrm{~N}\right]^{+}$} \\
\hline & $5 c$ & 80.16 & 80.05 & {$\left[\mathrm{C}_{5} \mathrm{H}_{6} \mathrm{~N}\right]^{+}$} \\
\hline
\end{tabular}




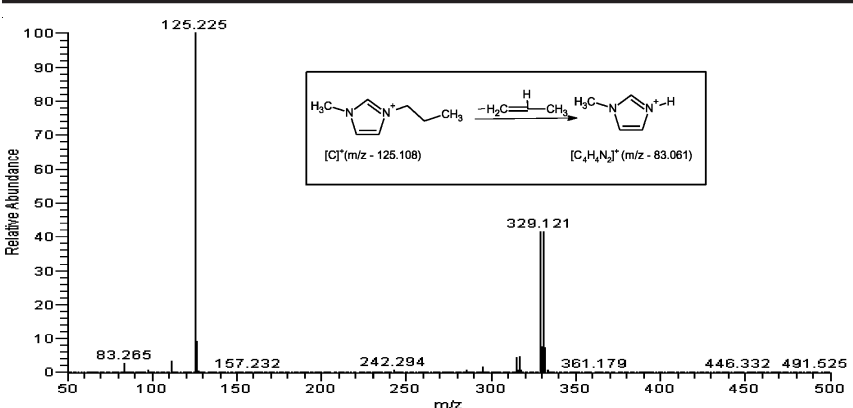

Fig. 3. ESI-MS/MS spectrum with the proposed pattern of fragmentation of compound 1-methyl-3-propylimidazolium bromide

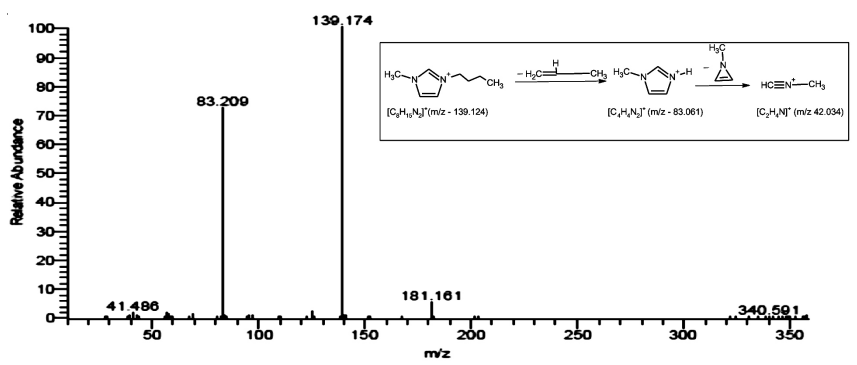

Fig. 4. ESI-MS/MS spectrum with the proposed scheme of fragmentation of compound 1-butyl-3-methylimidazolium bromide

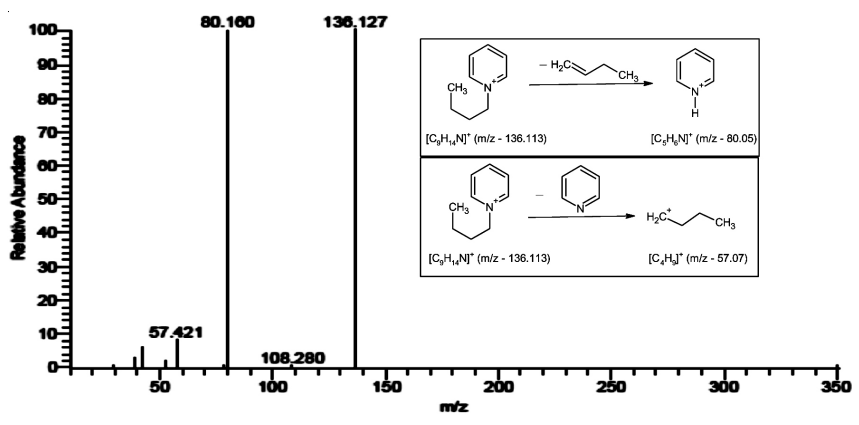

Fig. 5. ESI-MS/MS spectrum with the proposed pattern of fragmentation of compound $n$-butylpyridinium bromide

the basis of decomposition of tri- $n$-butyl ammonium system. We observed the peaks at $m / z=242.315,186.234,142.129$, $130.179,100.204,72.239,58.245$ (Table-1), respectively which are in harmony with the reported pattern. However, we observe additional peak resolutions at 446.348, 414.253, $349.848 \mathrm{~m} / \mathrm{z}$, respectively. These are being attributed to cation-cation-cation or cation-anion-cation association in gas phase.

The mass spectrum of tetrabutyl ammonium ion $(\mathrm{m} / \mathrm{z}=$ 242.165) can be accounted in terms of loss of neutral species (butene and propene), migration of a proton and the McLafferty rearrangements as shown in Scheme-I and reffering to Table-1. The imminium ion obtained at $\mathrm{m} / \mathrm{z}=58.245$ involves two consecutive classical McLafferty rearrangements, as shown in Scheme-I. The peak observed at $m / z=72.081$ is due to removal of ethylene from the $\mathrm{C}_{6} \mathrm{H}_{14} \mathrm{~N}^{+}(\mathrm{m} / z=100.113)$ ion.

The peak observed at $\mathrm{m} / \mathrm{z} 446.348$ is assigned to association of tri- $n$-butyl-ammonium ion and two ions of di- $n$-butylammonium ion (i.e., cation-cation-cation association). The $m / z 414.253$ peak can be viewed as a combination of tetrabutyl ammonium cation $(\mathrm{m} / \mathrm{z}=242.285), \mathrm{N}$-butyl-N-methyl imine cation $(\mathrm{m} / \mathrm{z}=100.113)$ and $\mathrm{N}$-ethyl-N-methyl imine cation $(m / z=72.081)$. A combination of di- $n$-butyl-ammonium ion and $\mathrm{N}, \mathrm{N}$-dibutyl-imminium cation with a bromine (anion) results in a species having molecular weight $\mathrm{m} / z=349.221$. All these means that there is a clusterization of ammonium ions in the form of triplet cation-cation-cation $(+++)$ or triplet cation-cation-anion $(++-)$ associations in gas phase.

The studies of excess thermodynamic properties of mixed aqueous solutions of electrolytes have assumed great interest in recent years, since these provide useful information on the interaction between ions of the same charge either triplet or high order interactions ${ }^{14}$. In light of this, we studied the gas phase behaviour of tetrabutyl ammonium bromide closely and which indicate the existence of the triplet ion $(+++)$ or $(++-)$ interactions in gas phase i.e., cation-cation-cation or cationanion-cation triplet forming species even in gas phase. We believe that interactions get attenuated in presence of water and lead to the concepts involving aggregation, micelles and hydrophobic interactions.

The mass spectral data of 1-ethyl-3-methylimidazolium bromide are tabulated in Table-1 (entry 2a-2c) and described in Fig. 2. It involves peaks at $m / z$ 303.113, 111.215 and 83.227. The 303.113 peak is assigned to formation of the class $\mathrm{C}_{2} \mathrm{~A}^{+}$. We proposed a pattern of fragmentation as shown in Fig. 3 (inset) for 1-ethyl-3-methylimidazolium bromide which involves migration of $\beta$-hydrogen, forming an imidazolium cation having mass 83.061 (entry $2 \mathrm{c}$ ).

The mass spectra of 1-methyl-3-propylimidazolium bromide reveals the peak at $\mathrm{m} / \mathrm{z} 83.265$ is the daughter ion of the parent having $m / z 125.225$ (Fig. 3). In the Table- 1 entry $3 a$ is the associated triplet $(++-)$ having $m / z=329.121$. We suggest a scheme on the basis of the peaks observed which are accounted in terms of a pattern of fragmentation as shown in Fig. 3. It shows loss of propene molecule through the migration of $\beta$-hydrogen.

The closer scrutiny of the mass spectrum of 1-butyl-3methylimidazolium bromide (Fig. 4) shows peaks at $\mathrm{m} / \mathrm{z}$ 139.174 which is the daughter ion of the parent which have $m / z=359$ (the associated triplet of +-+ ions). Similarly the peak at $\mathrm{m} / \mathrm{z} 139.174$ gives the daughter ion at $\mathrm{m} / \mathrm{z} 83.209$ (Table-1). The occurrence of these peaks as shown in Fig. 4 can be accounted with a scheme given in inset of Fig. 4. It includes pattern of fragmentation, where we have utilized the rearrangement in which $\beta$-hydrogen migrates with loss of neutral species (i.e., butene), resulting in an ion having $\mathrm{m} / \mathrm{z}$ 83.061 (entry 4c). Further interesting pattern of fragmentation is observed in the case of the peak at $\mathrm{m} / \mathrm{z} 41.486$, which involves removal of neutral species alkenes, propene, followed by loss of three member nitrogen heterocycle (i.e. aziridine).

The results depicted in Table-1 (entry 5a-5d) for $n$ butylpyridinium bromide show the peaks at $\mathrm{m} / \mathrm{z}=351.3$ [an associated triplet of +-+ ions], 136.127, 80.16 and 57.421 respectively. We suggest a pattern of fragmentation as described in Fig. 5 with a given scheme. It seems that the rearrangement concept utilized earlier helps us to identify the presence of ions having $\mathrm{m} / \mathrm{z}$, value very close to $5 \mathrm{~b}, 5 \mathrm{c}$ and $5 \mathrm{~d}$ ions.

Lattice energy of ammonium salts (particularly imidazolium and pyridinium) is responsible for their very low melting nature, 


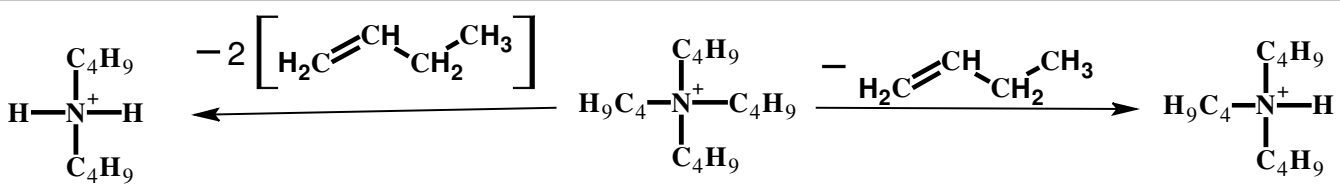

$\lg \left[\mathrm{C}_{8} \mathrm{H}_{20} \mathrm{~N}\right]^{+}(\mathrm{m} / \mathrm{z}-130.160) \quad 1 d\left[\mathrm{C}_{16} \mathrm{H}_{36} \mathrm{~N}\right]^{+}(\mathrm{m} / \mathrm{z}-242.285)$

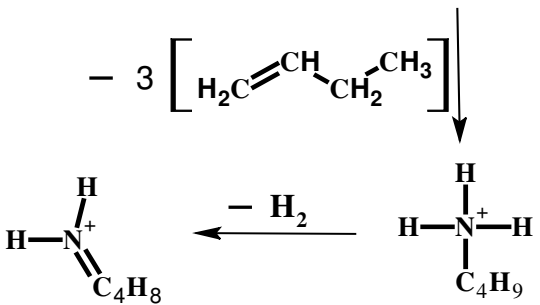

1i $\left[\mathrm{C}_{4} \mathrm{H}_{10} \mathrm{~N}\right]^{+}(\mathrm{m} / \mathrm{z}$ - 72.081)

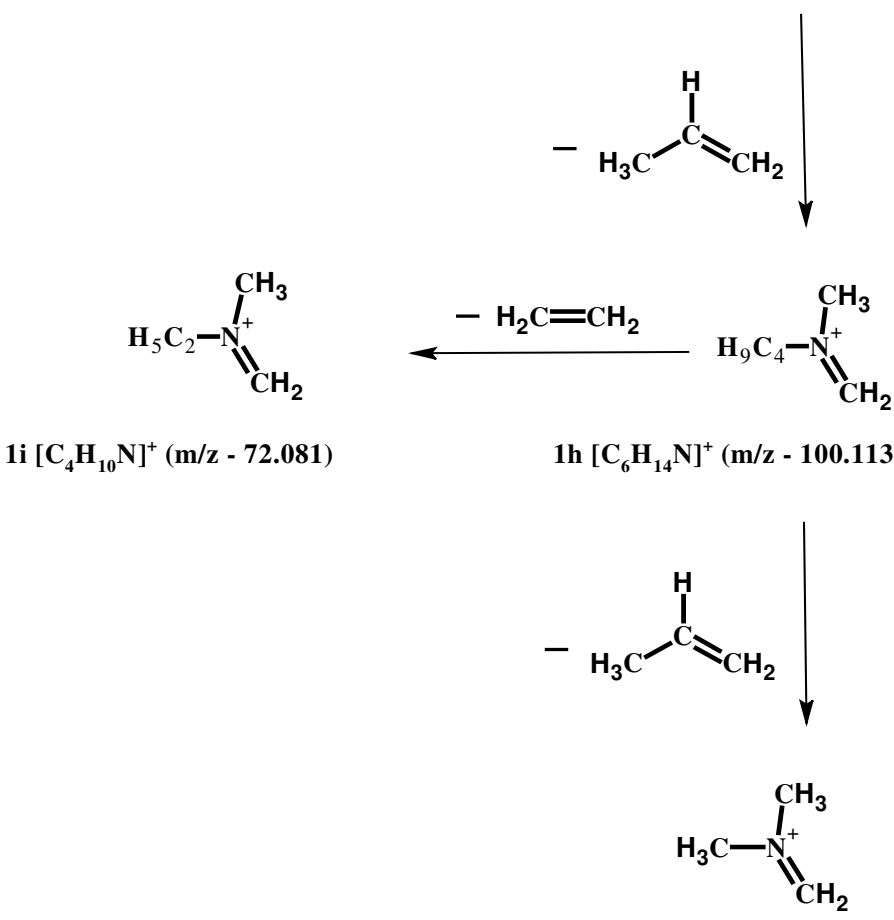

$1 \mathrm{e}\left[\mathrm{C}_{12} \mathrm{H}_{28} \mathrm{~N}\right]^{+}(\mathrm{m} / \mathrm{z}-186.222)$
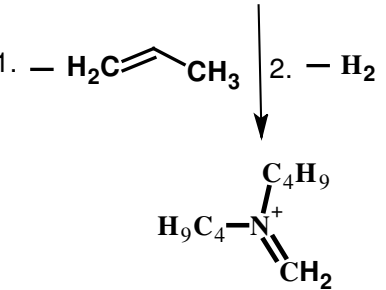

1f $\left[\mathrm{C}_{9} \mathrm{H}_{20} \mathrm{~N}\right]^{+}(\mathrm{m} / \mathrm{z}-142.159)$

$1 \mathrm{j}\left[\mathrm{C}_{3} \mathrm{H}_{8} \mathrm{~N}\right]^{+}(\mathrm{m} / \mathrm{z}$ - 58.066)

Scheme-I: Proposed pattern of fragmentation for tetrabutylammonium bromide

such compounds consist large cation and an anion that is very difficult to fit into the lattice. Mass spectra (Figs. 1-5) also indicate presence of associations for tetraalkylammonium ions, imidazolium ions and pyridinium ions in the form of triplet interaction species $\left(\mathrm{C}_{2} \mathrm{~A}\right)^{+}$. We believe that such association may be due to cation-cation affinity assisted by $\pi$ - $\pi$ stacking interaction due to the ring electrons. In the studies of physicochemical processes involved in the existance of ionic liquids (imidazolium and pyridinium salts), Dupont and Suarez have indicated the presence of $\pi-\pi$ stacking via weak C-H- $\pi$ interaction in methyl and imidazolium ring $\pi$ system in solid phase ${ }^{15}$. Such cation-cation $\pi-\pi$ stacking interaction have also been indicated in theoretical studies in gas phase ${ }^{16}$. Association of several imidazolium and pyridinium ions also has been postulated $\left(\mathrm{C}_{2} \mathrm{~A}\right)^{+}$by Gross $(9 \mathrm{e})$. It is difficult to quantify the energetics of such interactions, however the spectral, simulation and $a b$ initio studies do indicate the vital structural effects ${ }^{17}$. It can be suggested that such molecular arrangments can generate channels in which the bromide anion is accomodated as chains. The said structural pattern in the form $\mathrm{C}_{2} \mathrm{~A}^{+}$may be visualized in a form as given in Fig. 6.
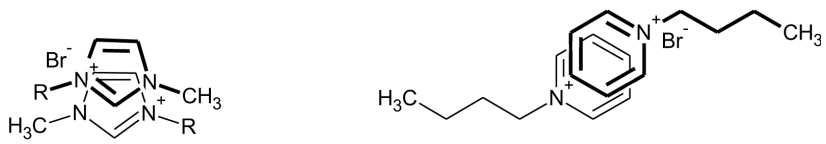

Where $\mathrm{R}-=$ b) $-\mathrm{C}_{2} \mathrm{H}_{5}$, c) $-\mathrm{C}_{3} \mathrm{H}_{7}$, d) $-\mathrm{C}_{4} \mathrm{H}_{9}$

Fig. 6. A associated triplets of imidazolium and pyridinium ions with bromide anion

\section{Conclusion}

Our mass spectral studies using the hyphenated technique "ESI-MS/MS" effectively elucidates the structure of ionic liquids through their mass spectra. The work reported herein avoids direct heating of ionic liquids (in short, minimizes the possibility of decomposition of the ionic liquids). Methanol is 
well suited to perform the analysis of the mentioned ionic liquids. The fragmentation patterns for ethyl, propyl and butyl imidazolium ions are accounted in terms of loss of neutral molecule like butene, iminium ion, substituted heterocycles, while in pyridinium salt a loss of butene molecule occurs. The possibilities of clusterization around $\mathrm{N}^{+}$centers and the formation of dimeric cationic species in vapour phase are indicated. The specific fragmentation pattern for tetrabutyl ammonium bromide is presented and discussed in terms of association of the ionic fragments even in gas phase.

\section{ACKNOWLEDGEMENTS}

The authors are thankful to Dr. V. P. Dhande for valuable guidance, as well as Mr. A. G. Rao, Principal of M. J. College, Jalgaon and Prof. Dr. D. G. Hundiwale, Director, Board of College and University Development, North Maharashtra University, Jalgaon, India for encouragement and facilities.

\section{REFERENCES}

1. (a) P. Hapiot and C. Lagrost, Chem. Rev., 108, 2238 (2008); (b) C.S Santos, S. Rivera-Rubero, S. Dibrov and S. Baldelli, J. Phys. Chem. C, 111, 7682 (2007).

2. R.J. Soukup-Hein, M.M. Warnke and D.W. Armstrong, Ann. Rev. Anal. Chem., 2, 145 (2009).

3. (a) M. Weishi and H.C. Tak, Acc. Chem. Res., 39, 897 (2006); (b) F.V. Rantwijk and R.A. Sheldon, Chem. Rev., 107, 2757 (2007); (c) J. Dupont, R.F. De-Souza and P.A. Z. Suarez, Chem. Rev., 102, 3667 (2002); (d) V.I. Parvulescu and C. Hardacre, Chem. Rev., 107, 2615 (2007)

4. B.L. Ackermann, M.J. Berna, J.A. Eckstein, L.W. Ott and A.K. Chaudhary, Ann. Rev. Anal. Chem., 1, 357 (2008).
5. S.J. Blanksby and T.W. Mitchell, Ann. Rev. Anal. Chem., 3, 433 (2010).

6. J.C.A. Wuilloud, S.R. Gratz, B.M. Gamble and K.A. Wolnik, Analyst, 129, 150 (2004).

7. H. Moriwaki, H. Harino, T. Yoshikura, T. Ohe, H. Nukaya, Y. Terao, H. Sawanishi, K. Wakabayashi, H. Miyakoda and J.-F. Alary, J. Environ. Monit., 6, 897 (2004).

8. T. Gruendling, S. Weidner, J. Falkenhagen and C.B. Kowollik, Polym. Chem., 1, 599 (2010)

9. (a) O. Bortolini, M. Bottai, C. Chiappe, V. Conte and D. Pieraccini, Green Chem., 4, 621 (2002); (b) B.L. Ackermann, A. Tsarbopoulos and J. Allison, Anal. Chem., 57, 1766 (1985); (c) Z.B. Alfassi, R.E. Huje, B.L. Milman and P. Neta, Anal. Bioanal. Chem., 377, 159 (2003); (d) P.J. Dyson, I. Khalaila, S. Luettgen, J.S. Mclndoe and D. Zhao, Chem. Commun., 2204 (2004); (e) J.H. Gross, J. Am. Soc. Mass Spectrom., 18, 2254 (2007); (f) G.P. Jackson and D.C. Duckworth, Chem. Commun., 522 (2004); (g) J.H. Gross, Mass Spectrometry; A Textbook, Springer-Verlag; Berlin Heidelberg, edn. 2, pp. 314-318 (2011); (h) A. Lesimple, O. Mamer, W. Miao and T.H. Chan, J. Am. Soc. Mass Spectrom., 17, 85 (2006); (i) P.J. Dyson, J.S. Mclndoe, D. Zhao, Chem. Commun., 508 (2003); (j) J.H. Gross, J. Am. Soc. Mass Spectrom., 19, 1347 (2008).

10. G.A. Jeffery and R.K. Mcmillan, Progr. Inorg. Chem., 8, 43 (1967).

11. W.Y. Wen, Water and Aqueous Solutions: Structure, Thermodynamics and Transport Processes, Willey Interscience, New York (1972).

12. H.G. Hertz and M.D. Zeilder, Ber. Bunsenges. Phys. Chem., 68, 821 (1964).

13. G.R. Gupta, G.R. Chaudhari, P.A. Tomar, G.P. Waghulade and K.J. Patil, Asian J. Chem., 24, 4675 (2012).

14. (a) W.Y. Wen, K. Miyajima and A. Otsuka, J. Phys. Chem., 75, 2148 (1971); (b) K. Patil and G. Mehta, J. Chem. Soc. Faraday Trans. 1, 84, 2297 (1988); (c) K. Patil and G. Mehta, J. Chem. Soc., Faraday Trans. 1, 83, 2467 (1987); (d) M. Holz and K.J. Patil, Ber. Bunsenges. Phys. Chem., 95, 107 (1991).

15. J. Dupont and P.A.Z. Suarez, Phys. Chem. Chem. Phys., 8, 2441 (2006).

16. H. Li, J.A. Boatz and M.S. Gordon, J. Am. Chem. Soc., 130, 392 (2008).

17. (a) J. Dupont, J. Braz. Chem. Soc., 15, 341 (2004); (b) Z. Meng, A. Dolle and W.R. Carper, J. Mol. Struct. (Theochem.), 502, 119 (2002). 